DR. TURNBULL'S FYE.REMEDIES. REPLY TO MR. DASENT.

To the Editor of The Lancer.

Sir:-In The Laveft of Saturday last, May 13, I observed a letter from Mr. Dasent, late house-surgeon to the Royal Westminster Ophthalmic Hospital, containing remarks on cases of diseases of the eyes, treated by Dr. Turnbull in that Institution, an account of which was published by Dr. Turnbull, in his recent work on Diseases of the Nerves and Lyes. As I applied the means in all these cases, and was the only individual present when the reports were drawn up and signed by the house-surgeons of the Institution, I think it but justice to Dr. Turnbull to give a plain statement of facts, which will clearly show what errors Mr. Dasent has committed in his letter. To make this evident, I shall give extracts from the original reports, which will be found to correspond with those contained in Dr. Turnbull's work, and from these it will be seen how far Mr. Dasent speaks correctly, when he declares that he did not sign the reports. The originals, in Mr. Dasent's handwriting, which I shall be happy to show to any one, are in my possession. When Mr. Dasent had left the hospital, his successor, Mr. Baillie, as a matter of course, drew up a report of the progress of the casss which remained, and which were three only out of the eleven. The originals of MIr. Baillie's reports are also in my possession. I shall only make remarks upon those cases in which there is disagreement between the accounts given by Dr. Turnbull and Mr. Dasent:-

First case. In this case the progress is a literal transcript from $\mathrm{Mr}$. Baillie's report.

Third case. Mr. Dasent states, that $D_{r}$. Turnbull and himself agree that there was no benefit derived, whereas the report and progress of the case, draun up and signed by himself, bear testimony that the man, " after having attended four or five times, left the hospital, because he could not be made an in-patient. Said he thought that there was some improvement."

Fifth case. I can bear testimony that this boy was unable to keep his eyelids open; Dr. Turnbull's remarks are, therefore, quite correct.

Seventh case. The inveteracy of this case calls forth Mr. Dasent's dissatisfaction, because Dr. Turnbull has remarked, that it would require considerable time to effect a cure. Mr. Dasent states, that no inveterate case of amaurosis was cured. Whether this be so or not, will be best seen by reading the report of the eighth case, as drawn up by Mr. Dasent himself, and taking into consideration that the patient had been, during the previous five months, under treat- ment in the Royal Westminster Ophthalmic Hospital, withont receiving the slightest benefit. 'The progress of the case was drawn up by Mr. Baillie.

Eighth case. "Nov. 14, 1936. Richard Wright, aged seventeen, residing at 7 , Noelstreet, Berwick-street, Soho, has suffered from impaired vision from infancy; is able with the left eye, half shut, to see objects tolerably well for a short time, at the distance of an arm's length, but cannot with the right eye distinguish objects ; he also suffers from strabismus. (Signed) Bury S. Dasent."

"Jan. 11, 1837. Right eye. Can distinguish pins from needles at a yard's distance, and pick them up when thrown upon the table. Can distinguish individuals. Sees objects with the left eye at usual distances, with the eyelids fully open; the left eye is perfect. (Signed) F. H. Ballite."

Ninth case. The whole of this case was drawn up and signed by Mr. Dasent. The cure of this case, which was very speedy, has called forth the dissatisfaction of Mr. Dasent, because Dr. Turnbull has not stat ed that it was curable by ordinary means; ordinary means had been tried without effect. Mr. Dasent does not state, under this case, how far the remedies succeeded, and whether Dr. 'I'urnbull's plan, or the ordinary one, is the more speedy and agreeable to the patients.

Tenth case. The whole of the report of this case was drawn up and signed by $M I r$. Dasent, who remarks, that the ulcer was healing in the ordinary course of things. His own report states, that " Nov. 30, 1836, after the fever, the left eye became inflamed, and when tried he could not distinguish a face or hand. There is an ulcer in the middle of the cornea, entirely concealing the pupil." In the first place, an ulcer concealing the whole pupil is a singular evidence of its healing; and, in the second place, Mr. Dasent's memory must be not a little treacherous, as he distinctly stated to me that the eye would burst from ulceration. The progress of the case is in Mr. Dasent's own words :-_" Dec. 30. With the left eye this patient can distinguish the front from the back of a shilling, and the front from the back of the hand, and the fingers. (Signed) Bury S. Dasent. Dec. 30, 1836." Eleventh case. To refute Mr. Dasent's remark, that this man was able to walk from Greenwich to London withont assistance, previously to his being put under Dr. Turnbull's care, I give a copy of the report and progress drawn up by the house-surgeons :-“Dec. 5, 1836. Alexander M'Pher" son, a Greenwich pensioner, aged forty-five, has been blind three years and a half; he can see light, but can distinguish no object beyond its shadow; caught a severe cold on board of ship, helping to extinguish a fire, after which he had a severe attack of 
rhenmatism, four years ago. (Signed) BURY S. Dasent."

"Jan. 16, 1837. After five applications he was able to come from Greenwich alone, and after six more could see to pick up a glove thrown upon the floor. Has had nothing done since the 6th Jall., from illness. (Signed) F. H. BaIlliE."

In the above remarks I have stated, not only in justice to Dr. Turnbull, but in justice to the efficient plan of treatment which he has struck out, the simple facts of the case. Presuming that Mr. Dasent's anxieties to advance the profession and benefit humanity are as intense as my own, 1 must nevertheless infer that he is singularly deficient in powers of memory. But "litera scripta manet." This is my only argument, and it is an effective one. I am, Sir, your obedient servant,

J. LYon, M.R.C.S., London.

25, Montague-street, Russell-square. May 15, 1837.

** Having published the charges of Mr. Dasent, and the foregoing statement in re. ply, we beg to observe, that we shall not have room in our pages for a single additional line which may uot prove to be essential to the elucidation of the truth respecting the points under cuntroversy.- ED. I.

\section{AMPUTATION AT THE KNEE-JOINT}

\section{EXPERIMENTAL MURDERS.}

To the Editor of The La NCET.

SIR:-I beg leave to communicate to you a few particulars relative to an operation which has long since been condemned by British surgeons as bad and impracticable, but which has been revived during the last session at the Hopital la Charité, of Paris, by M. Velpeau. I am, Sir, your obedient servant,

Tros. A. Burgess, M.R.C.S.

11, Caroline-street, Bedford-square, May, 1837.

The operation of amputating at the kneejoint has been revived by $M$. Velpeau, the daring surgeon of the Hopital la Charité, and performed three several times during the past winter, in cases of caries of the head of the tibia, the object of the operation being merely that of leaving the patient a better stump. The operation had been performed three times in the space of three or four months, in each of which cases it proved fatal about the serenth or ninth day from the time of the operation. In the last case there seemed to be no actual necessity for performing the operation, save that of experiment. The individual was a strong, robust man, with the exception of caries of the head of the tibia. His health and appetite were good, when he was admitted into the hospital. He might have lived for many years had not the operation been performed, with the comparatively slight inconvenience of a stiff joint, and it appeared quite unwarrantable tooperute in such a case. After the operation the wound was well plugged with charpie, and left to nature. The result was, that in the space of a few days innumerable abscesses had formed beneath the tendons and skin, all along the external side of the limb, as far as the hip.joint, which, together with the extensive suppuration going on in the wound itself, and the hectic fever that accompanied the formation of pus, completely ran down the patient in seven or eight days. At the post-mortem examination the limb seemed to be burnowed to a great extent, by matter, and the hip. joint was beginning to be affected, when death ensued. After the post-mortem, M. Velpeau stated that this being the third case in which he had tried this operation within the last few months, and all three of them haring terminated fatally, he now condemned the operation as being bad and im. practicable.

The operation, although perforned by $\mathrm{M}$. Velpean, was not countenanced by any of the other parisian surgeons. I mentioned the case to M. Jobert, surgeon l'Hopital $S t$. Louis, and he said that he did not think the operation at all practicable.

\section{ON PESSARIES,}

AND ON THE RADICAL CURE OF

\section{PROLAPSUS OF THE UTERUS AND VAGINA.}

\section{By Professor Dieffenbach, of Berlin.}

THE use of pessaries, so often employed in the practice of those who devote themselves to the treatment of the diseases of females, is attended with so many disagreeable and unfavourable circumstances, that a reform has become absolutely necessary.

The method which cousists in supporting the prolapsed uterus, or vagina, by the in. troduction of a solid foreign body, a pessary, into the genital organs, is just as rude and imperfect an operation as the introduction of a pessary, or other mechanical means, would be for the cure of prolapsus of the anus. When I reflect on the gratit inconveniences $I$ have seen arise from the nse of pessaries continued for a great length of time, and in many cases actually forgotten, in the genital orgaus of the female, \&c., I am almost inclined to banish them completely from my practice.

I have frequently seen them produce putrid discharges from the vagina; in other 